forum that would give non-governmental organizations, the drug industry and other stakeholders a say in shaping the WHO's policies. This is critical, say experts, as such stakeholders have key roles in global health. Member states fear a loss of their influence, however, and many observers are concerned at the risk of undue industry sway.

But some experts say the reform plans fail to explicitly address fundamental structural weaknesses in the WHO. One is its inability to set its own priorities. The agency has full control of only the $25 \%$ of its budget that comes from membership fees paid by member states. A whopping 75\% comes from voluntary contributions - funds that donor countries often earmark for their own pet projects. This skews the WHO's priorities, says Lawrence Gostin, head of the WHO Collaborating Center on Public Health Law and Human Rights at Georgetown University in Washington DC. "Around 60\% of the WHO's budget goes on infectious diseases, and just $3.9 \%$ on non-communicable diseases and $2.4 \%$ on injuries, yet these are a huge global health burden," he notes.

Cassels says that building greater trust in the WHO should result in fewer earmarks. But experts are also concerned that the proposals ignore an elephant in the room: the WHO's byzantine decentralized structure. Its six regional offices are autonomous to an extent seen in no other UN agency, electing their own heads, controlling large amounts of the WHO's funds and largely fixing their own policies. "At present, there are seven WHOs, not one," says Bloom.

"It's a birth defect" rooted in the WHO's creation from pre-existing regional bodies, says Kelley Lee, an expert on the WHO at the London School of Hygiene and Tropical Medicine. "It adds to the lack of cohesion and expansive agenda that spreads the WHO's limited resources ever more thinly." Cassels argues, however, that much improvement is possible within the existing decentralized organization. He says that Chan intends to take charge of an effort to "require much stronger monitoring of performance across all of the major offices".

Yet if deeper structural issues are not tackled, reforms will bring only "marginal" change, predicts Derek Yach, senior vicepresident of global health and agriculture policy at PepsiCo, headquartered in New York State, who was a cabinet secretary to former WHO director-general Gro Harlem Brundtland. And Lee thinks that fixing the WHO won't be enough to bring coherence to global health funding. "I believe that the biggest problem is that there are now so many institutional players in global health, and that there is a need to reform the whole chaotic landscape, not just one organization. It's like fixing a flat tyre when the whole car needs to be tuned up." -
ASTRONOMY

\section{Change rattles the world's biggest dish}

\section{BY EUGENIE SAMUEL REICH}

A s Earth's biggest 'ear' on the Universe, the giant 305-metre radio dish at Arecibo, Puerto Rico, has played a part in groundbreaking discoveries, searches for alien civilizations and the occasional Hollywood movie. Now a different sort of drama is shaking up the facility, with the news that Cornell University, which has managed Arecibo since the observatory was switched on 1963, has lost its bid to continue to do so. Instead, the US National Science Foundation (NSF) has offered the job - and the US\$41.2-million five-year contract that goes with it - to a consortium that includes SRI International, a non-profit research institute based in Menlo Park, California; the Universities Space Research Association in Washington DC; and the Metropolitan University in Puerto Rico.

The decision means an abrupt switch in the status of about 100 scientists, engineers and support staff at the observatory, who will no longer be on the Cornell payroll. "All of our staff are somewhat disoriented because they've been here 20,30, 40 years and never considered they wouldn't be Cornell employees," says Sixto González, assistant director of space and atmospheric science at Arecibo and the site's former director.

Rumours of the change first appeared on the Internet last week and have since been confirmed by Cornell. "We wish SRI good luck in living up to the incredibly high standards we have set," says Ira Wasserman, chairman of Cornell's astronomy department.

Robert Kerr, a former director of Arecibo who was principal investigator on the successful bid, says that, to ensure a smooth transition, for the first year nothing will change about how applications for time on the facility are processed. Beyond that, Kerr says, partners in the consortium are "likely to bring forward new ideas and new science".

One thing that will change right away is the location of the observatory's director Under Cornell, Arecibo's director was based remotely at the university's campus in Ithaca, New York. Under the consortium, the director - expected to be Kerr - will work on site.

Héctor Arce, an astronomer at Yale University in New Haven, Connecticut, who was born and raised in Puerto Rico, says it was widely felt that Cornell didn't do enough to partner with other institutions on the island. "That might have hurt Cornell," he says. In addition to including the Metropolitan University on the bid, the consortium will sponsor faculty positions at the University of Puerto Rico and will create a commission that will study other ways in which local institutions can get more involved with Arecibo.

Donald Campbell, a Cornell astronomer and the current director of the observatory, says Cornell submitted a serious proposal based on partnerships with seven institutions, including the University of Puerto Rico.

But Juan Arratia, an electrical engineer at the Metropolitan University in San Juan, says that the Puerto Rican government supported the SRI consortium's bid through the government-owned Puerto Rico Industrial Development Company, the office of tourism and the Department of Education. Arratia, who led Metropolitan's part of the bid, expects that government sources will contribute around \$5 million per year to the observatory. "That would be a real plus," says John Salzer, an astronomer at Indiana University Bloomington who works with data from Arecibo.

Astronomers rallied to support Arecibo after its closure was recommended in a 2006 NSF review. The facility is now likely to remain the most sensitive instrument of its kind for the foreseeable future. A 500-metre radio dish under construction in Guizhou, China, will not reach the higher frequencies that Arecibo can detect. The Square Kilometre Array, to be built in Australia or South Africa, would surpass Arecibo, but its construction is not expected to begin for several more years. 